\title{
Correction to: Low-threshold topological nanolasers based on the second-order corner state
}

Weixuan Zhang, Xin Xie, Huiming Hao, Jianchen Dang, Shan Xiao, Shushu Shi, Haiqiao Ni, Zhichuan Niu, Can Wang, Kuijuan Jin, Xiangdong Zhang and Xiulai Xu

Correction to: Light: Science \& Applications https://doi.org/10.1038/s41377-020-00352-1

published online 29 June 2020

Following publication of this article ${ }^{1}$, it was noted that Fig. $4 \mathrm{a}$ and $\mathrm{b}$ contained some errors.

The horizontal coordinates in $4 \mathrm{a}$ and $\mathrm{b}$ should be corrected to 1, 10, 100, 1000. The correct Fig. 4 is provided in this Correction.
The original article has been updated.

Published online: 13 August 2021

\section{Reference}

1. Zhang, W. et al. Low-threshold topological nanolasers based on the secondorder corner state. Light Sci. Appl. 9, 109 (2020).
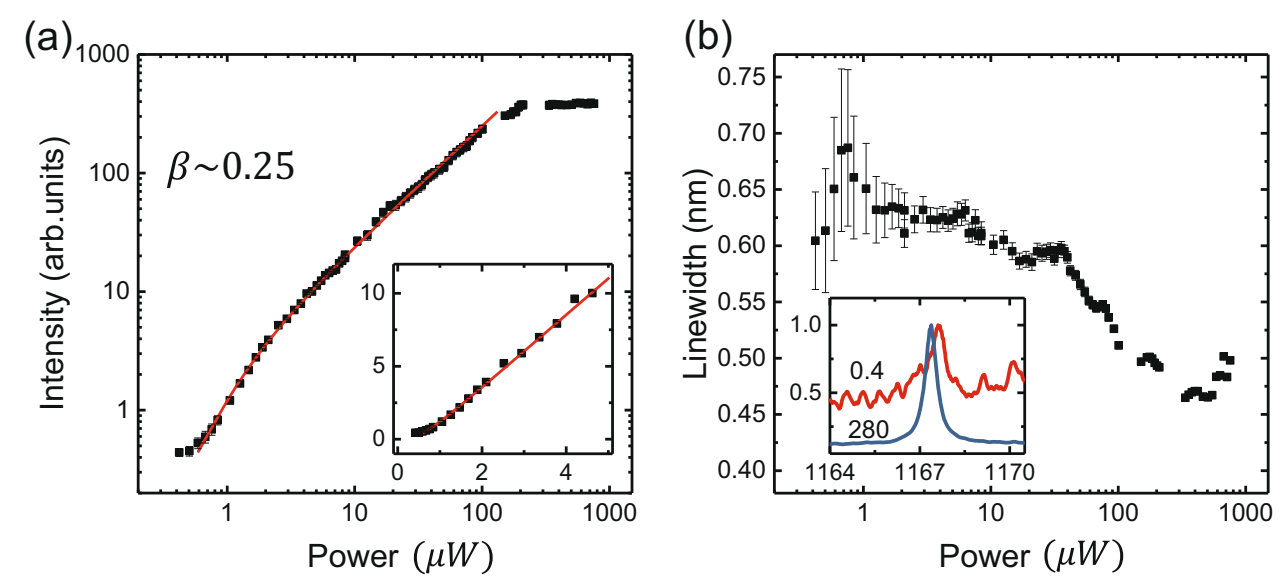

Fig. 4

(c) (i) Open Access This article is licensed under a Creative Commons Attribution 4.0 International License, which permits use, sharing, adaptation, distribution and reproduction c. in any medium or format, as long as you give appropriate credit to the original author(s) and the source, provide a link to the Creative Commons license, and indicate if changes were made. The images or other third party material in this article are included in the article's Creative Commons license, unless indicated otherwise in a credit line to the material. If material is not included in the article's Creative Commons license and your intended use is not permitted by statutory regulation or exceeds the permitted use, you will need to obtain permission directly from the copyright holder. To view a copy of this license, visit http://creativecommons.org/licenses/by/4.0/. 